University of Wollongong

Research Online

Faculty of Business - Papers (Archive)

Faculty of Business and Law

$1-1-2016$

Uncertainty, crowding aversion and tourism aversion in tourism

destinations

Simone Marsiglio

University of Wollongong, simonem@uow.edu.au

Follow this and additional works at: https://ro.uow.edu.au/buspapers

Part of the Business Commons

Research Online is the open access institutional repository for the University of Wollongong. For further information contact the UOW Library: research-pubs@uow.edu.au 


\title{
Uncertainty, crowding aversion and tourism aversion in tourism destinations
}

\begin{abstract}
The author analyses the implications of crowding aversion and tourism aversion for the economic performance of tourism destinations in the case of uncertain tourist inflows. He analytically characterizes all possible scenarios, showing how different preferences of tourists (towards crowding) and residents (towards tourism) interact and affect the economic outcome. The paper shows that when tourists are crowding-averse (crowding lovers), uncertainty leads to deterioration (improvement) of economic performance, while it does not affect performance at all when tourists are crowding-indifferent. However, assessing how this will be reflected in welfare changes is more complex, since it depends also on the degree of tourism aversion among local residents.
\end{abstract}

Copyright c 2014 IP Publishing Ltd. Reproduced by permission.

\section{Keywords}

aversion, tourism, uncertainty, destinations, crowding

Disciplines

Business

Publication Details

Marsiglio, S. (2016). Uncertainty, crowding aversion and tourism aversion in tourism destinations.

Tourism Economics: the business and finance of tourism and recreation, 22 (1), 111-123. 


\title{
Uncertainty, crowding aversion and tourism aversion in tourism destinations
}

\author{
SIMONE MARSIGLIO
}

University of Wollongong, School of Accounting, Economics and Finance, Northfields Avenue, Wollongong, NSW 2522, Australia.E-mail: simonem@uow.edu.au.

\begin{abstract}
The author analyses the implications of crowding aversion and tourism aversion for the economic performance of tourism destinations in the case of uncertain tourist inflows. He analytically characterizes all possible scenarios, showing how different the preferences of tourists (towards crowding) and residents (towards tourism) interact and affect the economic outcome. The paper shows that, when tourists are crowding-averse (crowding lovers), uncertainty leads to deterioration (improvement) of economic performance, while it does not affect performance at all when tourists are crowding-indifferent. However, assessing how this will be reflected in welfare changes is more complex, since it depends also on the degree of tourism aversion among local residents.
\end{abstract}

Keywords: uncertainty; tourism specialization; crowding aversion; tourism aversion

JEL classification: $\mathrm{O} 40 ; \mathrm{O} 41$

Tourism has recently been gaining more and more importance in modern economies, both in developed and developing countries. Its (beneficial and costly) effects on economic development are well-known and extensively documented (see Brida and Pulina (2010) for a recent survey). A large share of the literature analyses the implications of tourism specialization for economic development, both in the short run and long run, by applying econometric techniques to conduct empirical investigations. Much smaller is the portion of studies tackling the issue from a theoretical point of view (among others, see Schubert (2010) and Schubert et al (2011)). In particular two main approaches have been proposed to explain the relationship between tourism and growth: the most popular uses dynamic models of trade to show that a terms of trade effect determines whether growth and tourism move in the same direction

I am grateful to Paolo Figini and Natalie Stoeckl for insightful discussions giving birth to this work. I wish also to thank the Editor of Tourism Economics, Stephen Wanhill, and one anonymous referee for their constructive comments on an earlier draft of the paper. All errors and omissions are my sole responsibility. 
(Hazari and Sgro, 1995; Lanza et al, 2003); a different and most recent approach relies on hedonic prices to understand how residents' choices may affect tourist inflows, determining income and thus well-being (Cerina, 2007; Lozano et al, 2008). To the best of our knowledge, no study extends the analysis to consider how the uncertainty about the evolution of tourism demand and tourist inflows may affect the growth process of tourism destinations. This is absolutely relevant if we consider that tourism evolution is to a large extent unpredictable, and thus determining how to react to such randomness is essential to contrast (exploit) eventual harmful (beneficial) events. In order to shed some light on this issue, we follow the latter approach to consider how a stochastic tourism dynamics will affect economic performance and well-being in tourism-based economies.

Thus, the model we adopt relies on the framework proposed first by Cerina (2007) and later analysed by Lozano et al (2008) and Marsiglio (2015). Specifically, we consider a small economy producing only tourism services, supplied in an international tourism market populated by a large number of tourism economies; the notion of tourism services should be interpreted as a bundle of goods and services able to satisfy a wide range of tourism consumers (Candela and Figini, 2010). The tourist flows come from the international market and thus there is no distinction between resident and non-resident tourists. International demand for tourism is infinite at the price level corresponding to tourists' willingness to pay and nil for any other price level; thus, the equilibrium quantity of tourism is totally determined by the supply-side. ${ }^{1}$ Residents are characterized as traditional macroeconomic household-firm agents, who wish to maximize their lifetime utility given the dynamic evolution of tourism capital and tourist inflows. This formalization of the tourism market is very convenient, since it permits us to describe the tourism-economic problem as a standard macroeconomic (Ramsey-type) problem.

We depart from Cerina's (2007) approach in three different ways: we do not consider environment for the sake of simplicity; we allow for the utility of residents to depend also on the number of visitors entering the local economy; we assume that tourist inflows follow a stochastic process. Not considering environmental issues allows us to maintain the model as simple as possible and to fully characterize the implications of uncertainty on economic performance and well-being. Moreover, this implies that tourists' willingness to pay depends only on tourism services and the number of other visitors present in the host country $;^{2}$ this allows us to assess how a different degree of crowding aversion may affect the economic outcome. Introducing the number of tourists in the utility function of the residents captures three alternative situations: residents enjoy, are indifferent to or are bothered by the presence of international tourists in the local economy (see Meleddu (2014) for a survey on residents' welfare in tourism economies). Which of these situations is most relevant may change from country to country according to whether the (income) benefits from tourism specialization are larger than, equal to or smaller than the associated perceived (economic, social and environmental) costs. ${ }^{3}$ Describing the evolution of tourist inflows as a random process allows us to compare directly the stochastic and deterministic outcomes, understanding what is the role played by uncertainty on the development of tourism destinations. 
Given our framework, as will become clearer shortly, the nature of the relationship between tourism specialization and economic development (and well-being) is all but trivial. Indeed, two main factors, the aversion to crowding of international tourists and the aversion to tourism of local residents, determine the net impacts of tourism development on the hosting community. To the best of our knowledge, an explicit investigation of the mutual relationship between tourists and residents' preferences is not present in the literature, thus our paper represents a first attempt at filling this gap. The presence of stochastic shocks on the evolution of international tourist inflows complicates the picture even further. This brief paper proceeds as follows. The stochastic optimization problem is introduced and analytically solved in the next section, where we derive most of our results and we also analyse the deterministic version of the model in order to compare its outcome with the stochastic framework. The last section, as usual, contains concluding remarks and directions for future research. Most of the technicalities are presented in the Technical Appendix.

\section{The model}

The model is a standard Ramsey (1928) model of optimal growth where the social planner seeks to maximize the (expected) welfare of the society (that is, the residents) taking into account the economic and tourism dynamics. The welfare is the infinite discounted ( $\rho$ is the pure rate of time preference) sum of instantaneous utilities; the utility function is assumed to be isoelastic in its two arguments, consumption, $C(t)$, and tourists number, $N(t): u(C(t), N(t))=$ $\frac{C(t)^{1-\theta} N(t)^{\varepsilon(1-\theta)}-1}{1-\theta}$, where $\theta>0$ is the inverse of the intertemporal elasticity of substitution and $\varepsilon \in[-1,1]$ represents the weight of tourism in residents' preferences; a negative (positive) value of $\varepsilon$ represents the case in which residents suffer (enjoy) the presence of international visitors. Thus, $\varepsilon$ measures the degree of tourism aversion of local residents: if $\varepsilon>0$ residents are tourism lovers, if $\varepsilon>0$ tourism indifferent while if $\varepsilon>0$ tourism-averse. The tourist inflow is stochastic and is driven by a geometric Brownian motion: $d N(t)=\mu N(t) d t+$ $\sigma N(t) d W(t)$, where $\mu>0$ is the drift and $\sigma \geq 0$ the variance parameter, while $d W(t)$ is the increment of a Wiener process. The economic constraint is given by the law of motion of tourism capital, which igiven by the difference between residents' income, $Y(t)$, and consumption: $\dot{K}(t)=Y(t)-C(t)$. As in Cerina (2007), income totally depends upon tourism revenues, which are given by the product between tourists' willingness to pay for and the quantity of tourism services exchanged on the market. The willingness to pay depends on the stock of tourism services, $K(t)$, and the number of tourists in the tourism destination, and it is assumed to take a Cobb-Douglas form, $P(t)=A K(t)^{\alpha}$ $N(t)^{-\beta}$, where $\alpha \in(0,1)$ and $\beta \in(-1,1)$ measure tourists' sympathy toward tourism facilities and other visitors in the tourism destination, respectively. ${ }^{4}$ In particular, if $\beta>0$ tourists are crowding averse, if $\beta=0$ crowding indifferent and if $\beta<0$ crowding lover. For the sake of simplicity, it is assumed that each tourist buys one unit of tourism services, such that $Y(t)=A K(t)^{\alpha} N(t)^{1-\beta}$.

Taking initial conditions, $K(0)$ and $N(0)$, as given, the planning problem in 
the tourism-based economy consists of choosing the consumption level, considering the dynamic evolution of tourism capital and tourists number: ${ }^{5}$

$$
\begin{aligned}
& \max _{C(t)} W=\mathbb{E}\left[\int_{0}^{\infty} \frac{C(t)^{1-\theta} N(t)^{\epsilon(1-\theta)}-1}{1-\theta} e^{-\rho t} d t\right], \\
& \text { s.t. } \dot{K}(t)=A K(t)^{\alpha} N(t)^{1-\beta}-C(t), \\
& d N(t)=\mu N(t) d t+\sigma N(t) d W(t) .
\end{aligned}
$$

Note that, in our model, the number of tourists is an auxiliary variable; thus it is totally irrelevant for sufficiency issues related to the dynamic optimization problem. If this were not the case, we would need to impose some parameter restriction in order for the maximization problem to be concave, as in Marsiglio (2015). From the previous problem it is clear that the uncertainty about tourist numbers affects the well-being of the residents both directly and indirectly. Indeed, tourist numbers influence their instantaneous utility function (what we may label 'utility effect'), and determines the size of the tourism revenue (what we may refer to as 'income effect'). These two effects move in the same or opposite direction according to the type of preferences of both the residents (towards tourism, $\varepsilon$ ) and international tourists (towards crowding, $\beta$ ).

Define $J(K, N)$ as the maximum expected value associated with the above stochastic optimization problem. ${ }^{6}$ The Hamilton-Jacobi-Bellman (HJB) equation reads as:

$$
\rho J=\max _{C}\left\{\frac{C^{1-\theta} N^{\epsilon(1-\theta)}-1}{1-\theta}+J_{K}\left[A K^{\alpha} N^{1-\beta}-C\right]+J_{N} \mu N+\frac{1}{2} \sigma^{2} J_{N N} N^{2}\right\},
$$

where subscripts denote partial derivatives of $J$ with respect to the variables of interest. Differentiating Equation (4) with respect to consumption gives the following first order condition:

$$
C=J_{K}^{-\frac{1}{\theta}} N^{-\frac{\epsilon(1-\theta)}{\theta}}
$$

which substituted back into Equation (4) yields:

$0=\left(\frac{\theta}{1-\theta}\right) J_{K}^{-\frac{1-\theta}{\theta}} N^{\frac{\epsilon(1-\theta)}{\theta}}-\rho J+A J_{K} K^{\alpha} N^{1-\beta}+\mu J_{N} N+\frac{1}{2} \sigma^{2} J_{N N} N^{2}-\left(\frac{1}{1-\theta}\right) N^{1-\epsilon}$.

By applying the guess and verify method to the previous equation, it is possible to show that a closed form solution to the problem exists under a particular combination of parameter values (the proofs of the following propositions are presented in the Technical Appendix). 
Proposition 1. Assume that $\theta=\alpha$; then (6) has a solution given by:

$$
J(K, N)=\xi_{1} K(t)^{1-\alpha} N(t)^{\epsilon(1-\alpha)}+\xi_{2} N(t)^{\epsilon(1-\alpha)+1-\beta}+\xi_{3},
$$

where:

$$
\begin{aligned}
& \xi_{1}=\frac{\alpha^{\alpha}}{(1-\alpha)\left\{\rho-\mu \epsilon(1-\alpha)-\frac{1}{2} \sigma^{2} \epsilon(1-\alpha)[\epsilon(1-\alpha)-1]\right\}^{\alpha}} \\
& \xi_{2}=\frac{(1-\alpha) A \xi_{1}}{\rho-\mu[\epsilon(1-\alpha)+1-\beta]+\frac{1}{2} \sigma^{2}[\epsilon(1-\alpha)+1-\beta][\epsilon(1-\alpha)-\beta]} \\
& \xi_{3}=-\frac{1}{(1-\alpha) \rho} .
\end{aligned}
$$

Moreover the optimal consumption path is:

$$
c(t)=\Omega K(t),
$$

while the optimal path of tourism capital is:

$$
K(t)=e^{-\Omega t}\left[K(0)^{1-\alpha}+(1-\alpha) A \int_{0}^{t} e^{(1-\alpha) \Omega s} N(s)^{1-\beta} d s\right]^{\frac{1}{1-\alpha}},
$$

where $\Omega=\frac{\rho-\mu \epsilon(1-\alpha)-\frac{1}{2} \sigma^{2} \epsilon(1-\alpha)[\epsilon(1-\alpha)-1]}{\alpha}$.

Equation (8) states that at equilibrium there is a linear relationship between the optimal level of consumption and tourism capital. This result and the underlying assumption (the tourists' sympathy toward tourism facilities equals the inverse of the intertemporal elasticity of substitution) are standard in this stochastic optimization $\operatorname{setup}^{7}$ (Smith, 2007). Equation (9) describes the relationship between the stock of tourism capital and the number of tourists, which is crucially affected by the degree of crowding aversion of international tourists and the presence of randomness in the evolution of tourist inflows.

In order to assess the impact of uncertainty on the economic performance of the tourism destination, we need to understand how the tourism capital stock relates to the degree of crowding aversion and the stochastic process driving the evolution of tourist numbers over time. In particular, by relating to Jensen's inequality, we can compare the deterministic and the stochastic outcomes of the model. Indeed the sign of $\beta$ directly determines whether the random process $N(t)$ is subject to a concave, convex or linear transformation in Equation (9), which allows us to directly contrast $\mathbb{E}\left[N(t)^{1-\beta}\right]$ and $(\mathbb{E}[N(t)])^{1-\beta}$. It is then straightforward to compare economic performance (as measured by the tourism capital stock, $\left.K(t)^{1-\alpha}\right)$ in the stochastic and deterministic framework. It is therefore possible to prove that: 
Proposition 2. Uncertainty tends to improve the economic performance of a tourism destination whenever tourists are crowding lovers $(\beta<0)$, while it tends to reduce its economic performance whenever tourists are crowding-averse $(\beta>0)$. Instead, if tourists are crowding-indifferent $(\beta=0)$ then uncertainty does not affect economic performance.

Proposition 2 shows how uncertainty, the type of preferences of international tourists and economic performance (of a tourism destination) are related. If the crowding aversion parameter is positive then uncertainty will be harmful for the economy, if it is negative then uncertainty will benefit the economy, while if it is null uncertainty will not have any influence at all on the economic outcome. Note that using consumption or income as an indicator of economic performance rather than tourism capital will not change the results since from Equation (8) there is a one-to-one relationship between consumption and capital, and income monotonically rises with capital. In terms of policy implications, this result suggests that uncertainty about the evolution of tourism does not necessarily hurt the economic system of tourism destinations, and assessing the direction of these effects requires a careful consideration of the characteristics of international tourists' preferences, which determine how income and uncertainty are related (through the income effect).

Note that economic performance and well-being are different and not necessarily positively related, since social welfare depends both on consumption and tourists number. Thus, in order to understand how uncertainty will impact the well-being of residents we need to understand how Equation (1) is affected by tourism shocks. In particular, the sign of $\beta$ and $\varepsilon$ determine whether the income and utility effects move in the same or opposite direction, and the magnitude of these parameters determines which of the two effects dominates. When they move in the same direction it is straightforward to assess their impact on wellbeing; when they do not the net effect depends on which effect dominates (further details can be found in the Technical Appendix). This result can be summarized as follows.

Proposition 3. The effect of uncertainty on the well-being of the local residents of a tourism-based economy depends on two factors: the sign and magnitude of the crowding aversion $(\beta)$ and the tourism aversion $(\varepsilon)$ parameters.

Proposition 3 shows that assessing the welfare effects of tourism shocks is particularly complex. The relationship between well-being and uncertainty depends on the preferences of two different types of agents: residents and international tourists. In the case in which residents are tourism-averse or indifferent, it is relatively easy to evaluate the direction of welfare effects (apart from the crowding averse case). In the case in which residents are tourism lovers, disentangling the impact of randomness on well-being is much more complex and requires precise knowledge of the size of the crowding aversion and tourism aversion parameters (see the Appendix). Note that these results are derived in a framework where $\varepsilon$ is simply a parameter, and thus constant over time. However as explained by Doxey's (1975) Irridex model and Butler's (1980) tourist area life cycle model, residents' perception of benefits and costs is likely to change over time according to the stage of tourism development. ${ }^{8}$ Thus, in reality, when $\varepsilon$ endogenously evolves over time, assessing net welfare effects will be even more difficult. 


\section{The deterministic case: $\sigma=0$}

We now briefly look at what we can add to our previous conclusions by analysing a special case of the model, that is the deterministic case, namely $\sigma=0$. If uncertainty does not play any role tourist inflows grow over time at an exogenous (and strictly positive) rate, $\mu: \dot{N}(n)=\mu N(t)$. In such a framework, it is possible to analytically derive the solution of Equation (9):

$$
\begin{aligned}
K(t) & =\left\{\left[K(0)^{1-\alpha}-\frac{(1-\alpha) A N(0)^{1-\beta}}{(1-\alpha) \Omega+(1-\beta) \mu}\right] e^{-(1-\alpha) \Omega t}\right. \\
& \left.+\frac{(1-\alpha) A N(0)^{1-\beta}}{(1-\alpha) \Omega+(1-\beta) \mu} e^{(1-\beta) \mu t}\right\}^{\frac{1}{1-\alpha}} .
\end{aligned}
$$

From the previous equation it is clear that in the long run tourism capital, and thus economic performance, will continue to rise for any $\beta \in(-1,1)$, as long as the trend of tourist inflows, $\mu$, is positive. Indeed, there is a one-to-one relationship between the growth in tourist inflows and the economic growth rate, since along the balanced growth path (BGP) equilibrium ${ }^{9}$ we have:

$$
\begin{aligned}
& \gamma_{N}=\mu>0, \\
& \gamma=\gamma_{K}=\gamma_{C}=\gamma_{Y}=\frac{1-\beta}{1-\alpha} \gamma_{N}=\frac{(1-\beta) \mu}{1-\alpha}>0,
\end{aligned}
$$

where $\gamma_{N}, \gamma_{K}, \gamma_{C}$ and $\gamma_{Y}$ represent the growth rate of tourist inflows, tourism capital, consumption and income, respectively. It is definitely more interesting to understand the nature of the relationship between increases in tourist inflows and residents' well-being in a deterministic framework. Since in such a case it is possible to explicitly compute also social welfare:

$$
\begin{aligned}
W & =\frac{(1-\alpha)^{-\alpha}[\rho-\epsilon(1-\alpha) \mu]^{-\alpha} N(0)^{\epsilon(1-\alpha)}}{\alpha^{1-\alpha}}\left[\alpha K(0)^{1-\alpha}+\right. \\
& \left.+\frac{\alpha(1-\alpha) A N(0)^{1-\beta}}{\rho-[\epsilon(1-\alpha)+1-\beta] \mu}\right]-\frac{1}{\rho(1-\alpha)},
\end{aligned}
$$

this requires only to determine the sign of the following derivative:

$$
\begin{aligned}
\frac{\partial W}{\partial \mu} & =\frac{\epsilon(1-\alpha)^{1-\alpha}[\rho-\epsilon(1-\alpha) \mu]^{-\alpha-1} N(0)^{\epsilon(1-\alpha)}}{\alpha^{-\alpha}}\left[\alpha K(0)^{1-\alpha}+\right. \\
& \left.+\frac{\alpha(1-\alpha) A N(0)^{1-\beta}}{\rho-[\epsilon(1-\alpha)+1-\beta] \mu}\right]+ \\
& +\frac{(1-\alpha)^{1-\alpha}[\rho-\epsilon(1-\alpha) \mu]^{-\alpha} A N(0)^{\epsilon(1-\alpha)+1-\beta}[\epsilon(1-\alpha)+1-\beta]}{\alpha^{-\alpha}\{\rho-[\epsilon(1-\alpha)+1-\beta] \mu\}^{2}}
\end{aligned}
$$


By analysing the previous expression it is clear that $\partial \mathrm{W} / \partial \mu>0, \forall \beta \in(-1,1)$ as long as $\varepsilon \geq 0$. When $\varepsilon<0$, instead, $\partial \mathrm{W} / \partial \mu<0$ if $\varepsilon \geq-(1-\beta) /(1-\alpha)$, while the sign of $\partial \mathrm{W} / \partial \mu$ is ambiguous whenever $\varepsilon>-(1-\beta) /(1-\alpha)$. In this latter case, the impact of $\mu$ on well-being depends on the magnitude of several parameters; in particular, not only the type of preferences of tourists $(\alpha$ and $\beta$ ) or the kind of preferences of residents $(\varepsilon)$, but also the stage of tourism development, in terms of stock of tourism facilities and visitors number $(K(0)$ and $N(0))$, determine the net welfare effect. We have just proved the following result:

Proposition 4. In the deterministic case, increases in tourist inflows (that is, rises in $\mu$ ) lead to improvements in the well-being of the tourism destination whenever residents are tourism lovers or indifferent $(\varepsilon \geq 0)$. If residents are tourism-averse $(\varepsilon<0)$, this may or may not be the case according to the stage of tourism development $(K(0)$ and $N(0)$ ), the size of the crowding aversion $(\beta)$ and the tourism aversion $(\varepsilon)$ parameters.

The results highlighted by Proposition 4 are intuitive: when residents are not bothered by the presence of visitors an increase in their number will generate higher profits improving residents' well-being; when they are tourismaverse, this is not so obvious and other factors need to be taken into account. Moreover, Proposition 4 provides some theoretical foundation to the literature emphasizing how residents' acceptance of tourism development is crucial for the long-term success of tourism in a specific destination (Andriotis and Vaughan, 2003). However, this is only one possibility for tourism growth to be reflected in improvements in residents' well-being, since it represents the case in which income and utility effects move in the same direction, increasing welfare. Note that a similar result may occur even if residents are averse to tourism and $\varepsilon$ is not too small (see the Appendix); this case refers to the situation in which the income effect more than offsets the (negative) utility effect, thus overall increasing well-being. This suggests that, if the aim of policymakers in tourism destinations is not only to improve economic performance but also steadily to increase residents' welfare, several elements need to be considered to identify the appropriate policy tools to achieve such a goal. Most of the studies in tourism economics do not consider the possible interactions between residents' and tourists' preferences, and consequently the derived policy recommendations often lack a global view of the complex relationship between tourism activities and the hosting economy.

\section{Conclusion}

This paper sheds light on the relationship between the uncertainty and preferences of both local residents and international tourists in tourism destinations. We develop a stylized model that allows us to assess how economic development due to tourism specialization will be affected by the randomness in tourist inflows and thus in tourist numbers. We show that the degree of crowding aversion (in tourists' preferences) determines whether economic performance will be enhanced, unaffected or lowered by such an uncertainty, and this is related to the sign of the income effect. However, how such changes in economic outcomes will be reflected in welfare variations is more complex and depends also on the degree of tourism aversion (in residents' preferences), which deter- 
mines the sign of the utility effect. This means that understanding how a tourism-based economy should respond to increasing uncertainty about future tourism developments in order to improve the well-being of its inhabitants is not simple and requires a broad range of information (that is, whether the income or utility effect is larger). We also consider the deterministic case in order to assess how tourism development will affect residents' welfare in the absence of uncertainty. We show that, if residents are tourism lovers or indifferent, then their well-being will rise as tourism increases, while if they are tourism-averse this may or may not happen according to the magnitude of several parameters, related to preferences (of both tourists and residents) and the stage of tourism development. Thus, even when uncertainty is not an issue, disentangling how the income and utility effects impact residents' well-being is all but trivial.

Note that our analysis so far has been intentionally simple in order to stress how any kind of economic evaluation becomes more complex when uncertainty is also taken into account. However, the need for such a simplistic approach precludes us from analysing both environmental and sustainability matters related to tourism specialization, and heterogeneity issues in the characteristics of tourist and resident agents. Thus, it is natural to wonder whether and how our results will change in such more complicated contexts. Moreover, our analysis has been purely theoretical, and it would be interesting to test the model empirically. In particular, the investigation of how tourists' willingness to pay for (avoiding) crowding affects residents' well-being (through the utility effect) is essential in order to prescribe policy recommendations aiming to increase not only economic performance but also social welfare. These further extensions are left for future research.

\section{Endnotes}

1. We are well aware of the limitations of this assumption. However, introducing also a demand side in such a dynamic context would complicate dramatically the model (which results to be already not trivial because of the presence of uncertainty), and it would no longer be possible to obtain analytical solutions.

2. Mcconnell and Sutinen (1984) first point out how tourism growth (in the sense of increasing number of visitors) may reduce tourist inflows when tourists are averse to crowding and facilities are congested (that is, the tourism product is a snob good). Several papers attempt to measure visitors' perceptions about crowding; the empirical results are mixed (Price and Chambers, 2000, and references therein), and so it is important to understand whether and how the results differ when tourists are crowding averse or crowding lovers.

3. Tourism development may generate costs, such as increased pressure on fragile environments, erosion of sites, unwelcome sociocultural effects, road congestion and the crowding out of attractions (Dwyer and Forsyth, 1997). However, tourism activity may also bring benefits, such as greater awareness of the local environment and culture, conservation of man-made monuments and wildlife preservation (Norton and Roper-Lindsay, 1992). How these benefits and costs are perceived by residents is not obvious, and may change over time. Several papers point out how some local communities have rejected tourism (Aziz, 1995; Sindiga, 1996) while others have embraced it (Wilson, 1994; Oakes, 1999).

4. Alternatively, the parameters $\alpha$ and $\beta$ can be interpreted in terms of price elasticity of demand for tourism services.

5. Given Cerina's (2007) specification of tourism activities, the model resembles to a large extent a canonical economic growth Ramsey-type problem, in which $K(t)$ would be traditionally interpreted as physical capital and $N(t)$ as population size.

6. See Chang (2004) for a detailed description of the procedures and methods we may use to solve 
stochastic maximization problems. Explaining how to derive and obtain an analytical solution to the HJB equation is beyond the scope of this paper. What we want to stress here, by providing a straightforward application, is that stochastic optimization can be used also to provide interesting insights on tourism-related problems.

7. Note that in the economic growth literature, $Y(t)$ is mainly interpreted as output while $\alpha$ and $\beta$ as factor shares. Thus, the condition $\theta=\alpha$ states an equality between the capital share and the inverse of the intertemporal elasticity of substitution. Such a restriction is needed when a production input evolves randomly, and this may be the case of technology (Smith, 2007) or labour (Marsiglio and La Torre, 2012a, 2012b).

8. The Irridex (irritation index) model describes how the irritation of residents increases as the number of tourists increases; four stages (euphoria, apathy, irritation and antagonism) are identified, and each stage corresponds to a different number of visitors and a different level of integration between residents and tourists. Similarly, the tourist area life cycle model states that there is a correlation between resident' attitudes and the different phases of development experienced by tourism destinations.

9. A BGP equilibrium is defined as a situation in which all variables grow at constant (and possibly positive) rates.

\section{References}

Andriotis, K., and Vaughan, R.D. (2003), 'Urban residents' attitudes toward tourism development: the case of Crete', Journal of Travel Research, Vol 42, pp 172-185.

Aziz, H. (1995), 'Understanding attacks on tourists in Egypt', Tourism Management, Vol 16, pp 9195.

Brida, J.G., and Pulina, M. (2010), 'A literature review on the tourism-led-growth hypothesis', working paper CRENoS 2010/17.

Butler, R.W. (1980), 'The concept of a tourist area cycle of evolution: implications for management of resources', Canadian Geographer, Vol 24, pp 5-12.

Candela, G., and Figini, P. (2010), 'Is there any economics beyond tourism areas?', Review of Economic Analysis, Vol 2, pp 256-271.

Chang, F.R. (2004), Stochastic Optimization in Continuous Time, Cambridge University Press, Cambridge.

Cerina, F. (2007), 'Tourism specialization and environmental sustainability in a dynamic economy', Tourism Economics, Vol 13, pp 553-582.

Doxey, G.V. (1975), 'A causation theory of visitor-resident irritants, methodology and research inferences', in Proceedings of the Sixth Annual Conference of the Travel Research Association, San Diego, CA, Travel and Tourism Research Association.

Dwyer, L., and Forsyth, P. (1997), 'Measuring the benefits and yield from foreign tourism', International Journal of Social Economics, Vol 24, pp 223-236.

Hazari, B.R., and Sgro, P. (1995), 'Tourism and growth in a dynamic model of trade', Journal of International Trade \& Economic Development, Vol 4, pp 243-252.

Lanza, A., Temple, P., and Urga, G. (2003), 'The implications of tourism specialization in the long run: an econometric analysis for 13 OECD economies', Tourism Management, Vol 24, pp 315-321.

Lozano, J., Gómez, C.M., and Rey-Maquieira, J. (2008), 'The TALC hypothesis and economic growth theory', Tourism Economics, Vol 14, pp 727-749.

Marsiglio, S. (2015), 'Economic growth and environment: tourism as a trigger for green growth', Tourism Economics, Vol 21, No 1, pp 183-204.

Marsiglio, S., and La Torre, D. (2012a), 'Population dynamics and utilitarian criteria in the LucasUzawa model', Economic Modelling, Vol 29, pp 1197-1204.

Marsiglio, S., and La Torre, D. (2012b), 'A note on demographic shocks in a multi-sector growth model', Economics Bulletin, Vol 32, pp 2293-2299.

Mcconnell, K.E., and Sutinen, J.G. (1984), 'An analysis of congested reservation facilities', Advances in Applied Micro-Economics, Vol 3, pp 9-36

Meleddu, M. (2014), 'Tourism, residents' welfare and economic choice: a literature review', Journal of Economic Surveys, Vol 28, pp 376-399.

Oakes, T. (1999), 'Eating the food of the ancestors: place, tradition, and tourism in a Chinese frontier river town', Ecumene, Vol 6, pp 123-145.

Norton, D.A., and Roper-Lindsay, J. (1992), 'Conservation, tourism and commercial recreation: conflict or cooperation - a New Zealand perspective', Natural Areas Journal, Vol 12, pp 20-25. 
Price, C., and Chambers, M.T.W. (2000), 'Hypotheses about recreational congestion: tests in the forest of Dean (England) and wider management implications', in Font, X., and Tribe, J., eds, Forest Tourism and Recreation, CABI Publishing, New York.

Ramsey, F. (1928), 'A mathematical theory of saving', Economic Journal, Vol 38, pp 543-559.

Schubert, S.F. (2010), 'Coping with externalities in tourism: a dynamic optimal taxation approach', Tourism Economics, Vol 16, pp 321-343.

Schubert, S.F., Brida, J.G., and Risso, W.A. (2011), 'The impacts of international tourism demand on economic growth of small economies dependent on tourism', Tourism Management, Vol 32, pP 377-385.

Sindiga, I. (1996), 'International tourism and marginalization of Swahili', Tourism Management, Vol 17 , pp 425-432.

Smith, W.T. (2007), 'Inspecting the mechanism exactly: closed-form solution to a stochastic growth model', B.E. Journal of Macroeconomics, Vol 7, No 1, Article 30.

Wilson, D. (1994), 'Unique by a thousand miles: Seychelles tourism revisited', Annals of Tourism Research, Vol 21, pp 20-46.

\section{Technical Appendix}

In order to derive an explicit solution for the HJB equation, as in (6), we need first to express our guess. Our educated guess (see Smith, 2007) in this framework may take the following form:

$$
J(K, N)=\xi_{1} K^{\lambda_{1}} N^{\lambda_{2}}+\xi_{2} K^{\lambda_{3}}+\xi_{3}
$$

Substituting its derivatives with respect to $K$ and $N$ into (6), yields:

$$
\begin{aligned}
& 0=\left(\frac{\theta}{1-\theta}\right)\left(\lambda_{1} \xi_{1}\right)^{-\frac{1-\theta}{\theta}} K^{-\frac{(1-\theta)\left(\lambda_{1}-1\right)}{\theta}} N^{\frac{(1-\theta)\left(\epsilon-\lambda_{2}\right)}{\theta}}+ \\
& +\xi_{1} K^{\lambda_{1}} N^{\lambda_{2}}\left[-\rho+\mu \lambda_{2}+\frac{1}{2} \sigma^{2} \lambda_{2}\left(\lambda_{2}-1\right)\right]+ \\
& +A \lambda_{1} \xi_{1} K^{\lambda_{1}-1+\alpha} N^{\lambda_{2}+1-\beta}+\xi_{2} N^{\lambda_{3}}\left[-\rho+\mu \lambda_{3}+\frac{1}{2} \sigma^{2} \lambda_{3}\left(\lambda_{3}-1\right)\right]-\left(\frac{1}{1-\theta}\right)-\rho \xi_{3} .
\end{aligned}
$$

Now suppose that: $\lambda_{1}=1-\theta=1-\alpha, \theta=\alpha, \lambda_{2}=\varepsilon(1-\theta)=\varepsilon(1-\alpha)$ and $\lambda_{3}=\varepsilon(1-\alpha)+1-\beta$; then we will have:

$$
\begin{aligned}
0 & =\left[\left(\frac{\alpha}{1-\alpha}\right)(1-\alpha)^{-\frac{1-\alpha}{\alpha}} \xi_{1}^{-\frac{1}{\alpha}}-\rho+\mu \epsilon(1-\alpha)+\frac{1}{2} \sigma^{2} \epsilon(1-\alpha)[\epsilon(1-\alpha)-\right. \\
& -1]] \xi_{1} K^{1-\alpha} N^{\epsilon(1-\alpha)}+\left[\xi _ { 2 } \left(-\rho+\mu[\epsilon(1-\alpha)+1-\beta]-\frac{1}{2} \sigma^{2}[\epsilon(1-\alpha)+\right.\right. \\
& \left.+1-\beta][\epsilon(1-\alpha)-\beta])+A(1-\alpha) \xi_{1}\right] * N^{\epsilon(1-\alpha)+1-\beta}-\left[\rho \xi_{3}+\frac{1}{1-\alpha}\right]
\end{aligned}
$$

Therefore, for this equation to be verified at each time, $t=0, \ldots, \infty$, the square brackets need to vanish and this may happen when the parameters $\xi_{1}, \xi_{2}, \xi_{3}$, take the values determined in Proposition 1. The optimal rule for consumption, as in Equation (8), is obtained by replacing $J_{K}$ and $J_{N}$ into Equation (5) with 
their expressions from Equation (12). Then by substituting Equation (8) into the state equation, we get:

$$
\dot{K}(t)=A K(t)^{\alpha} N(t)^{1-\beta}=\Omega K(t),
$$

which is a (stochastic) Bernoulli-type differential equation. Its solution is given in Proposition 1. Finally, the transversality condition requires that $\lim _{t \rightarrow \infty} E$ $\left[e^{-\rho t} J(K, N)\right]=0$, which because of our guess reads as:

$$
\lim _{t \rightarrow \infty} e^{-\rho t}\left(\xi_{1} \mathbb{E}\left[K^{1-\alpha} N^{\epsilon(1-\alpha)}\right]+\xi_{2} \mathbb{E}\left[N^{\epsilon(1-\alpha)+1-\beta}\right]+\xi_{3}\right)=0 .
$$

In order for this expression to hold, we need to analyse how the value of $\beta$ affects the previous equation, and the involved expected values. A sufficient condition for the three terms in the previous equation to converge to zero independently of the value of $\beta$ is $\phi \equiv[\varepsilon(1-\alpha)+2] \mu+1 / 2 \sigma^{2}[\varepsilon(1-\alpha)+2][\varepsilon(1-\alpha)+1]$ $-\rho<0$. Note that the unique role of the technical condition $\phi<0$ is to ensure that the transversality condition is met, ruling out explosive paths.

In order to contrast the stochastic and deterministic version of the model, we need to understand how $N^{1-\beta}$ behaves when subject to shocks and when not. By Jensen's inequality, we know that for $\chi=1-\beta \in(0,1)$, that is when $\beta$ > 0 , the random process $N$ under a strictly concave transformation will show $\mathbb{E}\left[N(t)^{x}\right]<(\mathbb{E}[N(t)])^{\chi}$; this implies that for $K(t)$ we obtain:

$$
\begin{aligned}
& \mathbb{E}\left[K(t)^{1-\alpha}\right]=e^{-\Omega t}\left[K(0)^{1-\alpha}+(1-\alpha) A \int_{0}^{t} e^{(1-\alpha) \Omega s} \mathbb{E}\left[N(s)^{\chi}\right] d s\right]^{\frac{1}{1-\alpha}} \leq \\
& \leq e^{-\Omega t}\left[K(0)^{1-\alpha}+(1-\alpha) A \int_{0}^{t} e^{(1-\alpha) \Omega s}(\mathbb{E}[N(s)])^{\chi} d s\right]^{\frac{1}{1-\alpha}}=(\mathbb{E}[K(t)])^{1-\alpha} .
\end{aligned}
$$

For $\chi=1-\beta \in(1,2)$, namely when $\beta<0$, the results are completely reversed; the random process $N$ under a strictly convex transformation will show $\mathbb{E}\left[N(t)^{\chi}\right]$ $>(\mathbb{E}[N(t)])^{\chi}$; this implies that $\mathbb{E}\left[K(t)^{1-\alpha}\right] \geq(\mathbb{E}[K(t)])^{1-\alpha}$. Finally, for $\chi=1-\beta$ $=1$, that is as long as $\beta=0$, we have a linear transformation which yields $\mathbb{E}\left[N(t)^{\chi}\right]=(\mathbb{E}[N(t)])^{\chi}$ and thus $\mathbb{E}\left[K(t)^{1-\alpha}\right]=(\mathbb{E}[K(t)])^{1-\alpha}$.

Provided that the parametric restriction in Proposition 1 is met, then the expressions in Equations (8) and (9) hold for any $t=0, \ldots, \infty$. Thus, taking into account that the value function reads as in (7), by plugging (8) into (1), and substituting (9) into the derived expression, the expected welfare reads as:

$$
W=\mathbb{E}\left[\int_{0}^{\infty} \frac{\Omega^{1-\alpha} K(t)^{1-\alpha} N(t)^{\epsilon(1-\alpha)}-1}{1-\alpha} e^{-\rho t} d t\right] .
$$

After some algebra, it is possible to show that the relationship between uncertainty and welfare depends on the sign of the following term: $\psi \equiv \mu[1-$ $\beta+\varepsilon(1-\alpha)]+\frac{1}{2} \sigma^{2}\{\varepsilon(1-\alpha)[\varepsilon(1-\alpha)-1]-\beta(1-\beta)\}$. Specifically, uncertainty will increase or decrease welfare according to whether $\partial \psi / \partial \sigma$ is positive or negative. Thus, it is convenient to analyse welfare implications of uncertainty under three alternative scenarios: 
(i) Consider first that tourists are crowding lovers $(\beta<0)$. If residents are tourism-averse or tourism-indifferent $(\varepsilon \leq 0)$, uncertainty will increase welfare; if residents are tourism lovers $(\varepsilon>0)$, uncertainty will increase welfare if $\varepsilon$ is large enough $(\varepsilon \leq 1 /(1-\alpha))$; otherwise how uncertainty and welfare are related will depend on whether the income or the utility effect prevails.

(ii) Consider the case in which tourists are crowding-indifferent $(\beta=0)$. If residents are tourism-averse $(\varepsilon<0)$, uncertainty will increase welfare; if residents are tourism-indifferent $(\varepsilon=0)$, uncertainty will not affect welfare; if residents are tourism lovers $(\varepsilon>0)$, uncertainty will increase welfare if $\varepsilon$ is large enough $(\varepsilon>1 /(1-\alpha))$, decrease welfare if it is small enough $(\varepsilon$ $<1 /(1-\alpha)$ ), not affect welfare if $\varepsilon=1 /(1-\alpha)$.

(iii) Finally, consider the crowding-averse tourists case $(\beta>0)$. If residents are tourism-averse $(\varepsilon<0)$, how uncertainty and welfare are related will depend on whether the income or the utility effect is larger; if residents are tourism-indifferent $(\varepsilon=0)$, uncertainty will decrease welfare; if residents are tourism lovers $(\varepsilon>0)$, uncertainty will decrease welfare if $\varepsilon$ is small enough $(\varepsilon \leq 1 /(1-\alpha))$, otherwise how uncertainty and welfare are related will depend on whether the income or the utility effect prevails.

Intuitively, these results are related to the direction and intensity of the income and utility effects. 